\title{
UM ESTUDO MULTICASO QUANTO À RELAÇÃO ENTRE OS MANUAIS DO USUÁRIO E A LEGISLAÇÃO VIGENTE
}

\author{
N. M. C. ARAÚJO*, M. O. MEDEIROS, M. R. SILVA \\ InstitutoFederaldeEducação, CiênciaeTecnologia da Paraíba \\ nelmamca@gmail.com*
}

Artigo submetido em 14/08/2017 e aceito em 17/09/2019

DOI: $10.15628 /$ holos.2019.6217

\section{RESUMO}

A Indústria da Construção Civil difere das demais em muitos aspectos, apresentando peculiaridades que refletem uma estrutura dinâmica e complexa. Entre essas peculiaridades, destacam-se às relativas ao tamanho das empresas, à curta duração das obras, à sua diversidade e à rotatividade da mão de obra (Araújo, 2008). Essa indústria também possui grande representatividade econômica, tanto no cenário internacional quanto no nacional, ocupando posição de destaque na composição do Produto Interno Bruto (PIB). A necessidade de se estabelecer parâmetros de qualidade para as obras de edificações tem sido uma demanda dos intervenientes do setor da construção civil. 0 foco no desempenho vem ao encontro dessa necessidade, com o estabelecimento de exigências a serem atendidas, bem como a forma de mensurá-las. Nesse sentido, se evidencia a importância da elaboração do Manual do Usuário pelas empresas construtoras de edificações. Este artigo apresenta parte de uma pesquisa que teve como objetivo maior elaborar um diagnóstico quanto à contribuição do Manual do Usuário para a qualidade e desempenho das edificações verticais construídas pelas empresas construtoras da grande João Pessoa - PB. Os resultados apontam que os manuais são elaborados apenas para cumprir um requisito legal e que a qualidade de construção e o desempenho das obras não possuem relação com o conteúdo dos manuais.

PALAVRAS-CHAVE: Construção de Edifícios, Qualidade, Desempenho, Manual do Usuário.

\section{A MULTICATHETIC STUDY ON THE RELATIONSHIP BETWEEN USER MANUALS AND CURRENT LEGISLATION}

\begin{abstract}
The Civil Construction Industry differs from the others in many ways, presenting peculiarities that reflect a dynamic and complex structure. Among these peculiarities are those related to the size of the companies, the short duration of the works, their diversity and the turnover of the workforce (Araújo, 2008). This industry also has great economic representativeness, both in the international scenario and in the national scenario, occupying a prominent position in the composition of the PIB. The need to establish quality parameters for building works has been a demand of the construction industry stakeholders. The focus on performance meets this need, with the
\end{abstract}

establishment of requirements to be met, as well as how to measure them. And it is in this sense that it is evident the importance of the elaboration of the User Manual by the construction companies of buildings. This article presents part of a research whose main objective was to elaborate a diagnosisabout the contribution of the User Manual to the quality and performance of the vertical constructions built by the construction companies of the great João Pessoa. The results indicate that the manuals are only designed to meet a legal requirement and that the quality of construction and performance of the works are not related to the content of the manuals.

KEYWORDS: Building Construction, Quality, Performance, User Manual. 


\section{INTRODUÇÃO}

O acesso à habitação é fundamental para a qualidade de vida de uma pessoa. A moradia é considerada uma necessidade básica ou fisiológica, ou seja, está diretamente ligada à existência e à sobrevivência do ser humano.

Segundo olBGE (2010), o Brasil temum déficithabitacional de 6.859.255 novas habitações urbanas, recebendo na última década um incremento da ordem de 10,17\% e reforçando, assim, a tendência de urbanização crescente do país. Constata-se, assim, que tão importante quanto reduzir o déficit habitacional é promover moradias dignas à população.

Para Tamaki (2010), o que existia até então, em termos de leis e normas, tratava apenas dos sistemas construtivos, procedimentos e materiais, não havia um parâmetro ou uma forma de medir se as edificações estavam correspondendo às expectativas dos usuários. Essa situação fazia com que construtores e consumidores não tivessem uma referência clara de quais requisitos a edificação deveria atender.

Para preencher essalacuna, a Associação Brasileira de Normas Técnicas (ABNT) publicou em 2013 a Norma de Desempenho para Edificações Habitacionais, a NBR 15575 (ABNT, 2013). Ela estabelece requisitos e critérios para edificações com base nas exigências dos usuários, considerando 0 desempenho mínimo que cada sistema componente da edificação deve alcançar.

Além disso, a norma estabelece as incumbências dos diversos intervenientes atuantes no processo, destacando a participação do usuário na manutenção das edificações seguindo o disposto no Manual de Uso, Operação e Manutenção. A ABNT, através da NBR 14037 (ABNT, 2011), estabelece as diretrizes para a elaboração desse manual.

Nesse contexto, cabe investigar se os manuais estão sendo elaborados conforme disposto na NBR 14037 (ABNT, 2011) e se estão contemplando os requisitos presentes na NBR 15575 (ABNT, 2013). Este artigo busca responder à seguinte questão: Os manuais do usuário elaborados pelas empresas construtoras de edificações verticais da grande João Pessoa têm contribuído para a qualidade e desempenho dessas edificações?

Nos últimos anos, a indústria da construção brasileira vem aumentando sua participação na economia nacional. Aproximadamente $15 \%$ do PIB (Produto Interno Bruto) brasileiro é do setor da construção (Câmara..., 2016), o que o torna um dos mais importantes ramos da produção do país. Todavia, a construção, nos moldes como é conduzida, apresenta-se em posição de destaque, também, por ser uma grande geradora de resíduos. Essa situação deve-se, em grande parte, por essa indústria ainda utilizar processos construtivos essencialmente manuais que geram perdas consideráveis. Quanto maior for a perda existente em um projeto (empreendimento), maior será o custo do empreendimento, menor será o lucro da empresa construtora/incorporadora e menor será a qualidade do produto.

Segundo Meseguer (1991), as origens das falhas de serviços em edifícios são variáveis, em termos percentuais, como mostra a Tabela 1. 
Tabela1-Origem dasfalhasdeserviçosemedifícios(em\%)

\begin{tabular}{|c|c|c|c|c|c|c|c|}
\hline & Bélgica & $\begin{array}{l}\text { Reino } \\
\text { Unido }\end{array}$ & Alemanha & Dinamarca & Romênia & Espanha & MÉDIA \\
\hline Projeto & 46 a 49 & 49 & 37 & 36 & 37 & 41 & $40-45$ \\
\hline Execução & 22 & 29 & 30 & 22 & 19 & 31 & $25-30$ \\
\hline Materiais & 15 & 11 & 14 & 25 & 22 & 13 & $15-20$ \\
\hline Uso & 8 a 9 & 10 & 11 & 9 & 11 & 11 & 10 \\
\hline \multicolumn{6}{|c|}{ Causas naturais imprevisíveis } & 4 & \\
\hline
\end{tabular}

A elaboração do Manual do Usuário se apresenta como ferramenta eficaz na busca da melhoriadaqualidadeedodesempenhodasedificações, reduzindoaspossíveisfalhasde uso.

Portanto, a relevância desse tema pode ser justificada tanto pelo resultado do produto ao se utilizar as recomendações contidas no Manual do Usuário, aumentando o desempenho da edificação e, consequentemente, a sua vida útil, quanto pela ausência de dados atualizados na literatura científica, no que diz respeito ao conteúdo dos manuais do usuário elaborados pelas empresas construtoras brasileiras e a relação existente entre o conteúdo destes e a melhoria da qualidade e do desempenho do produto (edificação).

\section{AINDÚSTRIA DA CONSTRUÇÃO}

Segundo Araújo (2008):

A Indústria da Construção Civil difere das demais em muitos aspectos, apresentando peculiaridades que refletem uma estrutura dinâmica e complexa. Entre essas peculiaridades, destacam-se às relativas ao tamanho das empresas, à curta duração dasobras, à sua diversidade eà rotatividade da mão deobra.

No aspecto econômico, ocupa papel de destaque no cenário mundial e nacional por gerar um grande número de empregos diretos e indiretos, absorvendo uma parcela considerável dos trabalhadores envolvidos em atividades industriais, um terço aproximadamente (Araújo, 2008).

De acordo com o IBGE (2014), as empresas de construção em 2012 realizaram incorporações, obras e serviços no valor de $\mathrm{R} \$ 336,6$ bilhões, registrando em termos reais expansão de 10,2\% na comparação com o ano anterior. Excluindo-se as incorporações, o valor das obras e serviços da construção atingiu $R \$ 326,1$ bilhões, sendo que deste montante $R \$ 114,1$ bilhões vieram das obras contratadas por entidades públicas, que representaram $35,0 \%$ do total das construções, participação menor do que a verificada em 2011 (38,4\%). A receita operacional líquida avançou 9,3\% em termos reais entre 2011 (R\$ 271,3 bilhões) e 2012 (R\$ 312,9 bilhões).

A indústria da construção ao longo do ano de 2012 foi influenciada positivamente por diversos fatores relacionados diretamente à dinâmica do setor, tais como: maior oferta de crédito imobiliário; crescimento do emprego e da renda; incremento no consumo das famílias; e manutenção da desoneração do Imposto sobre Produtos Industrializados (IPI) de diversos insumos da construção. Esse cenário favorável para a construção, juntamente com programas de 
Investimentos, como o Programa de Aceleração do Crescimento (PAC) e o Programa Minha Casa, Minha Vida, contribuíram para que fossem realizados investimentos em obras de infraestrutura e na construção de edificações residenciais, cujos investimentos são feitos considerando prazos de longa maturação.

Além disso, a indústria da construção tem grande participação na composição do PIB (Produto Interno Bruto) nacional, como mostram as Tabelas 2, 3, 4 e 5.

Tabela 2 - Dados gerais da Indústria da Construção - Brasil (2011 e 2012)

\begin{tabular}{|c|c|c|c|c|c|c|c|c|c|}
\hline \multirow{3}{*}{ Ano } & \multicolumn{9}{|c|}{ Dados gerais da Indústria da Construção } \\
\hline & $\begin{array}{c}\text { Número de } \\
\text { empresas } \\
\text { ativas }\end{array}$ & $\begin{array}{l}\text { Pessoal } \\
\text { ocupado }\end{array}$ & $\begin{array}{c}\text { Salários, } \\
\text { retiradase } \\
\text { outras } \\
\text { remunera- } \\
\text { ções }\end{array}$ & $\begin{array}{c}\text { Gastos } \\
\text { com } \\
\text { pessoal }\end{array}$ & $\begin{array}{l}\text { Total dos } \\
\text { custos e } \\
\text { despesas }\end{array}$ & $\begin{array}{c}\text { Valor das } \\
\text { incorporações, } \\
\text { obras e serviços }\end{array}$ & $\begin{array}{l}\text { Valor das } \\
\text { obras e } \\
\text { serviços }\end{array}$ & \begin{tabular}{|c|} 
Construções \\
para \\
entidades \\
públicas
\end{tabular} & $\begin{array}{l}\text { Receita } \\
\text { operacional } \\
\text { líquida }\end{array}$ \\
\hline & \multicolumn{2}{|c|}{1.000} & \multicolumn{7}{|c|}{ 1.000.000 R\$ } \\
\hline 2011 & 93 & 2.659 & 49.742 & 74.551 & 242.461 & 289.695 & 275.750 & 105.028 & 271.314 \\
\hline 2012 & 104 & 2.814 & 60.317 & 90.478 & 278.313 & 336.591 & 326.085 & 114.083 & 312.879 \\
\hline
\end{tabular}

Fonte: IBGE (2014).

Tabela 3 - Produto Interno Bruto (a preços de mercado) - Total Brasil

\begin{tabular}{c|c|c}
\hline Ano & $\begin{array}{c}\text { PIB-apreçoscorrentesem R\$ } \\
\text { milhões }\end{array}$ & Variação Anual (\%) \\
\hline 2009 & 3.333 .039 & $(0,1)$ \\
2010 & 3.885 .847 & 7,5 \\
2011 & 4.373 .658 & 3,9 \\
2012 & 4.805 .913 & 1,9 \\
2013 & 5.316 .455 & 3,0 \\
\hline
\end{tabular}

Fonte: IBGE apud CBIC (2016)

Tabela 4 - Valor Adicionado Bruto (a preços básicos) - Construção Civil

\begin{tabular}{c|c|c}
\hline Ano & $\begin{array}{c}\text { VABpbConstruçãoCivil-a preços } \\
\text { correntesemR\$ milhões }\end{array}$ & Variação Anual (\%) \\
\hline 2009 & 154.624 & 7,0 \\
2010 & 206.927 & 13,1 \\
2011 & 233.544 & 8,2 \\
2012 & 265.237 & 3,2 \\
2013 & 291.541 & 4,5 \\
\hline
\end{tabular}

Fonte: IBGE apud CBIC (2016). 
Tabela5-Participação(\%)noValorAdicionadoBruto(apreçosbásicos)- segundo as classes e atividades

\begin{tabular}{c|c|c|c|c|c}
\hline \multirow{2}{*}{ Ano } & \multirow{2}{*}{ Agropecuária } & \multicolumn{2}{|c|}{ Indústria } & \multicolumn{2}{c}{ Serviços } \\
\cline { 3 - 6 } & & Total & Construção Civil & Total & $\begin{array}{c}\text { Ativ. Imob.e } \\
\text { Aluguéis }\end{array}$ \\
\hline 2009 & 5,2 & 25,6 & 5,4 & 69,2 & 8,7 \\
2010 & 4,8 & 27,4 & 6,3 & 67,8 & 8,3 \\
2011 & 5,1 & 27,2 & 6,3 & 67,7 & 8,5 \\
2012 & 4,9 & 26,1 & 6,5 & 69,0 & 8,9 \\
2013 & 5,3 & 24,9 & 6,4 & 69,8 & 9,3 \\
\hline
\end{tabular}

Fonte: IBGE apud CBIC (2016).

\section{MANUTENÇÃO}

A manutenção de edifícios pode ser definida como um "conjunto de atividades a serem realizadas paraconservarou recuperaracapacidadefuncionaldaedificaçãoe desuas partesafim de atender às necessidades e segurança dos seus usuários" (ABNT, 2011). Desse modo, a previsão e o planejamento das possíveis intervenções ao longo da vida útil dos edifícios são fundamentais para reduzir o aparecimento de anomalias.

Entretanto, o tema manutenção planejada, citado em conferências e seminários, ainda não encontrou uma gama efetiva de contribuições em termos de aplicação com a definição de seu conteúdo e áreas de intervenção (Gasparoli e Scaltritti, 2011).

A manutenção preventiva, quando feita por meio de intervenções regulares e planejadas, é essencial para conservação e eficácia da destinação da edificação (Rocha, 2007). Também é importante para a segurança do usuário que essa manutenção seja realizada periodicamente. Segundo Shebalj (2010), estudos constatam que $66 \%$ das prováveis causas e origens dos acidentes em edificações com mais de dez anos estão relacionados à deficiência com a manutenção, perda precoce de desempenho e deterioração acentuada.

Outro aspecto importante da realização periódica da manutenção é que ela também evita aperda de garantia da edificação, uma vez que, segundo o Código de Defesa do Consumidor, o uso inadequado do bem isenta o construtor da responsabilidade sobre o defeito ou a anomalia que porventura vierem a acontecer (Castro, 2007).

\section{MANUALDE USO, OPERAÇÃO E MANUTENÇÃO}

A NBR 14037 (ABNT, 2011) "estabelece os requisitos mínimos para elaboração e apresentação dos conteúdos a serem incluídos no manual de uso, operação e manutenção das edificações elaborado e entregue pelo construtor e/ou incorporador, conforme legislação vigente". Segundo a norma, o manual tem por finalidade informar sobre as características técnicas do imóvel, descrever procedimentos recomendáveis para o melhor aproveitamento da edificação, orientar a realização das atividades de manutenção, prevenir a ocorrência de falhas e acidentes decorrentes de uso inadequado e contribuir para o aumento da durabilidade da edificação. 
O manual deve ser escrito em linguagem simples e direta apresentando as informações de forma didática, organizada e com nível de detalhamento compatível com a complexidade da edificação. $O$ seu conteúdo mínimo deve contemplar uma descrição da edificação como foi construída, incluindo projetos as built e "habite-se"; informações sobre os procedimentos para colocação da edificação em uso; recomendações sobre procedimentos de operação da edificação; instruções para situações de emergência; informações sobre inspeções técnicas; procedimentos recomendáveis para manutençãoe informaçõessobre responsabilidades egarantias.

\section{DESEMPENHO}

A necessidade de estabelecimento de parâmetros de qualidade para as obras de edificações tem sido uma demanda dos intervenientes do setor da construção civil. O foco no desempenho vem de encontro a essa necessidade, com o estabelecimento de exigências a serem atendidas, bem como a forma de mensurá-las.

O desempenho deve ser considerado desde a fase de concepção do edifício e ao longo do ciclo de vida da edificação. Em alguns países, como França, Canadá e Japão, o desempenho do produto-edifício e dos seus subsistemas é inicialmente definido para posteriormente serem definidas as tecnologias construtivas a serem adotadas (Oliveira e Mitidieri Filho, 2012).

Embora essa não seja a realidade encontrada no Brasil, visto que o desenvolvimento de projetos, de maneira geral, não considera a questão do desempenho, especialmente em projetos habitacionais (Melhado, 2001), esse quadro tende a mudar com a entrada em vigor da norma brasileira de desempenho, a NBR 15575 (ABNT, 2013).

A norma tem o foco no usuário do edifício habitacional e procura satisfazer suas necessidades de segurança (estrutural; contra o fogo; no uso e operação), habitabilidade (estanqueidade; desempenho térmico, acústico e lumínico; saúde, higiene e qualidade do ar; funcionalidade e acessibilidade; conforto tátil e antropodinâmico) e sustentabilidade (durabilidade; manutenibilidade; impacto ambiental). No entanto, ela não possui o intuito de substituir normas prescritivas. A própria NBR 15575 recomenda que haja simultaneidade na utilização das duas modalidades, de forma a "atender o usuário com soluções tecnicamente adequadas" (ABNT, 2013).

A NBR 15575 (ABNT, 2013) traz em seu escopo a clara atribuição da responsabilidade da manutenção da edificação ao usuário, desde que este receba da construtora e/ou incorporadora um manual que o oriente nesse sentido. Os itens referentes à manutenção contidos nessa norma representam um incremento ao conteúdo do manual, especificamente voltado para a garantia da vida útil de projeto da edificação.

\section{METODOLOGIA}

\subsection{Tipo de Pesquisa}

Considerando-se o critério de classificação de pesquisa proposto por Vergara (2009), quanto aosfinsequantoaosmeios, a pesquisa realizadaclassifica-seem exploratória edescritiva, quantoaosfins,e decampo, bibliográfica eparticipante, quantoaosmeios deinvestigação. 


\subsection{Universo e Amostra}

O universo da pesquisa foi composto pelas empresas construtoras de edificações verticais cadastradasjuntoaoSindicatodaIndústriadaConstruçãoCivil deJoãoPessoa(Sinduscon-JP).

Já a amostra, foi composta por onze empresas construtoras que aceitaram participar da pesquisa. Todas as empresas possuíam, no momento da pesquisa, manuais do usuário elaborados e entregues, relativos a obras de edificações verticais já construídas na grande João Pessoa. Ao todo foram pesquisados quinze manuais do usuário.

\subsection{Coleta de Dados}

A coleta de dados se deu em dois momentos: no primeiro momento, com relação à pesquisa bibliográfica; no segundo, com relação à pesquisa documental e decampo.

Na pesquisa bibliográfica, os dados foram coletados através de fichas resumos oriundas de teses, dissertações, monografias, artigos e livros que tinham relação com o tema da pesquisa.

Já na pesquisa documental, houve a análise do conteúdo dos manuais do usuário elaborados pelas empresas pesquisadas, enquanto que na pesquisa de campo, os dados foram coletados por meio de formulários e roteiros de observação, os quais foram elaborados a partir da pesquisa bibliográfica.

Antes da aplicação definitiva do formulário e do roteiro de observação, estes foram previamentetestados, comointuitodecorrigirdistorçõesqueporventuraseapresentassem.

Os formulários foram aplicados junto a gestores das empresas pesquisadas, enquanto que os roteiros de observação foram utilizados pelas pesquisadoras quando da visita in loco às edificações relacionadas aos quinze manuais do usuário pesquisados. Essas ferramentas buscaram identificar o conhecimento dos gestores quanto à elaboração/conteúdo dos manuais do usuário, bem como os benefícios oriundos de sua elaboração, no que diz respeito à qualidade e ao desempenho das edificações.

\subsection{Tratamento dos Dados}

Os dados foram tratados de forma quantitativa, utilizando-se procedimentos estatísticos, e qualitativa, através da estruturação e análise destes.

\section{RESULTADOS}

Todas as onze empresas pesquisadas atuam no mercado há mais de dez anos e são consideradas médias ou grandes empresas, tomando como referência o número de trabalhadores como critério de classificação (classificação adotada pelo Instituto Brasileiro de Geografia e Estatística IBGE).

Osquinzemanuaisanalisadossãomuito parecidos, noquedizrespeitoaoSumário, todavia, diferem um pouco na apresentação (capa, encadernação, impressão) enoconteúdo.

Após o início do tratamento dos dados referente à pesquisa nas 11 empresas e nos 15 manuais, pôde-se constatarque: 
- $\quad 87 \%$ (12) dos manuais pesquisados apresentam a descrição da edificação como construída, conforme requisito mínimo orientado pela NBR 14037;

- $\quad 93 \%(14)$ dosmanuaispesquisadosapresentamosprazoseascondições degarantia dos itens que compuseram a construção do imóvel, conforme requisito mínimo orientado pela NBR14037;

- $\quad 87 \%$ (12) dos manuais pesquisados apresentam identificação dos fornecedores de componentes, instalações e equipamentos, conforme requisito mínimo orientado pela NBR 14037;

- $\quad 67 \%$ (10) dos manuais pesquisados apresentam descrição dos riscos inerentes à edificação, mesmo em operação e uso normais, descrevendo procedimentos de segurança preventivosnecessários.

A avaliação da apresentação dos manuais elaborados nas onze empresas pesquisadas é positiva em relação à linguagem utilizada, porém, em alguns casos foi possível constatar uma repetição de textos em empreendimentos distintos. As empresas utilizam um padrão (modelo) para qualquer edificação da empresa, sematentar para as especificidades das obras.

\section{CONCLUSÕES}

A maioria das empresas pesquisadas elabora seus manuais em consonância com a NBR 14037 (ABNT,2011), apresentandoos requisitosmínimosorientadospela referidanorma.

Os manuais não vêm contribuindo com a qualidade e o desempenho das edificações, bem como não há qualquer preocupação por parte das empresas construtoras em iniciar a elaboração dos manuais quando iniciadas as primeiras atividades da obra.

A obra e os manuais são tratados pelas empresas construtoras de forma totalmente independentes, quantoàtemporalidade, àqualidade eao desempenho das edificações.

A responsabilidade da aplicação da NBR 15575 é distribuída entre os principais agentes do setor de construção civil, sendo a responsabilidade de demonstrar a qualidade do produto do fornecedor. Portanto, cabe aos fornecedores de materiais e produtos comprovarem 0 atendimento às normas técnicas, em geral prescritivas e anteriores à NBR 15575. Aos projetistas cabe especificar os requisitos dos materiais e produtos que devem ser utilizados, e às incorporadoras, ou construtoras, comprovarem o atendimento à norma de desempenho de seus sistemas e exigir comprovação de atendimento das normas técnicas relativas a materiais e produtos.

Os manuais, que devem ser elaborados à luz da NBR 14037, também devem estar em consonância com a NBR 15575, para que cumpra sua principal finalidade: informar sobre as características técnicas do imóvel, descrever procedimentos recomendáveis para o melhor aproveitamento da edificação, orientar a realização das atividades de manutenção, prevenir a ocorrência de falhas e acidentes decorrentes de uso inadequado e contribuir para o aumento da durabilidade da edificação.

Uma função importante dos manuais é proporcionar a comunicação objetiva e rápida entre os proprietários e as informações/procedimentos relativos ao uso adequado da edificação e consequente aumento da durabilidade.

Por fim, conclui-se que, infelizmente, atualmente os manuais ainda são elaborados apenas com o intuito de atender à legislação e não com o intuito de atender ao usuário. 


\section{REFERÊNCIAS}

ARAÚJO, N. M. C. (2008). Custos da implantação do PCMAT na ponta do lápis. 2. ed. São Paulo: Fundacentro.

ASSOCIAÇÃO BRASILEIRA DE NORMAS TÉCNICAS (2011). NBR 14037: Diretrizes para elaboração de manuais de uso, operação e manutenção de edificações - Requisitos para elaboração e apresentação dos conteúdos. Rio de Janeiro.

(2013).NBR15575:EdificaçõesHabitacionais-Desempenho.RiodeJaneiro,2013.

CÂMARA BRASILEIRA DA INDÚSTRIA DA CONSTRUÇÃO. Produto Interno Bruto(PIB)-Total Brasil. Recuperado em 12 fevereiro, 2016, de http://www.cbicdados.com.br/menu/pib-e- investimento/pib-brasil-econstrucao-civil.

CASTRO, U. R. (2007). A importância da manutenção predial preventiva e as ferramentas para sua execução. Monografia, UniversidadeFederaldeMinasGerais, BeloHorizonte,MG, Brasil.

GASPAROLI, P. e SCALTRITTI, M. (2011). Inspections and maintenance pogrammes for the conservation of historic architecture - some critical issues related to degradation and durability. Proceedings of the InternationalConferenceonDurabilityofBuilding MaterialsandComponents, Porto, Portugal, 12.

INSTITUTO BRASILEIRO DE GEOGRAFIA E ESTATÍSTICA (2010). Censo das cidades e regiões brasileiras. Recuperado em 1 março, 2014, de http://www.censo2010.ibge.gov.br/sinopse/index.php?dados=12.

INSTITUTO BRASILEIRO DE GEOGRAFIA E ESTATÍSTICA (2014). Pesquisa anual da indústria da construção 2012. v. 22. Rio de Janeiro: IBGE.

MELHADO, S. B. (2001). Gestão, cooperação e integração para um novo modelo voltado a qualidade do processo de projeto na construção de edifícios. Tese de Livre Docência, Escola Politécnica da Universidade de São Paulo, São Paulo, SP, Brasil.

MESEGUER, A. G. (1991). Controle e garantia da qualidade na construção. São Paulo: Sinduscon- SP.

OLIVEIRA, L. A. e MITIDIERI FILHO, C. V. (2012, maio). O projeto de edifícios habitacionais considerando a norma brasileira de desempenho: análise aplicada para as vedações verticais. Gestão e Tecnologia de Projetos, v. 7, n. 1, p. 90-100.

ROCHA, H. F. (2007). Importância da manutenção predial preventiva. Holos, v. 2, p 72-77.

SHEBALJ, V. L. C. C. (2010). Inspeção e manutenção predial. Série de cadernos técnicos CREA-PR. Recuperado em 8 abril, 2014, de http://docslide.com.br/documents/caderno-tecnico-crea-pr- inspecao-emanutencao-predial.html.

TAMAKI, L. (2010, maio). Vale o desempenho. Téchne, v. 1, n. 158, p 44-51.

VERGARA, S.C. (2009). Projetoserelatórios de pesquisaemadministração. 11.ed. São Paulo: Atlas. 